\title{
A SYSTEMIC APPROACH TO THE GROWTH OF KNOWLEDGE DRIVEN ECONOMY
}

\author{
Q.C. KANHUKAMWE ${ }^{1}$, P.B. SHARMA ${ }^{2}$, SANJEEV SHARMA ${ }^{3}$ \& S.K. GARG ${ }^{4}$ \\ ${ }^{1,2,3}$ Amity University, School of Engineering and Technology, Gurgaon, India \\ ${ }^{4}$ Delhi Technological University, School of Engineering and Technology, Delhi, India
}

\begin{abstract}
This paper presents a systematic approach to the growth of knowledge driven economy for developing nations. Knowledge driven economies are more sustainable as the dynamics of product market value is driven by new innovative technologies and optimally processes improved. The creation of an enabling environment by governments has resulted in the generation of several patents. However, most countries including India and Zimbabwe have failed to unlock value from the available intellectual property from their respective countries. The Indian economy has been performing well for the past two decades, the success has been based on the ability of the local population to consume the manufactured goods. However, the economies from developing nations have the potential to improve if the economies are turned to be knowledge driven economies. A review of different economies from the developed countries was carried out and benchmarked from those from the developing nations. The findings imply that it is essential for the nation to overcome barriers by implementing reliable strategies for their transition to knowledge economies and improving and enhancing appropriate investments in human capital, effective institutions, relevant technologies and innovative and competitive enterprises to facilitate such a transition. A systematic approach was designed in order to turn a developing nation into a more sustainable knowledge driven economy.
\end{abstract}

KEYWORDS: Economy, Knowledge, Sustainability, Research \& Commercialisation

Received: Jun 01, 2020; Accepted: Jun 21, 2020; Published: Jun 30, 2020; Paper Id.: IJMPERDJUN2020302

\section{INTRODUCTION}

The "knowledge based economy" is an expression coined to describe trends in advanced economies towards greater dependence on knowledge, information and high skill levels, and the increasing need for ready access to all of these by the business and public sectors (Boden and Miles, 2019). In its simplicity, it is the application of knowledge to develop goods and services. Scientific research, technological development and, particularly innovation, is, along with education and business information and communications technology, one of the pillars of building the knowledge society (Narunnabi, 2017). For the past two decades Zimbabwe has been creating a knowledge society through access to education and aggressive capacity building for universities and research centres in terms of human capital development (Friederici, 2019). Innovation hubs and science parks are currently being built, while India has managed to develop a knowledge society by 2010. India boost of both the knowledge society and the infrastructure for research and innovation (North and Kumta, 2018). However, the Indian economy still largely depends on the manufacturing sector (Berker et al., 2019) while the Zimbabwean economy is largely supported by agriculture (Fessehaie and Rustomjee, 2018). Both India and Zimbabwe are factor driven economies with India having started migrating slowly to the investment driven economy. This is evident of lack of utilisation of the 
knowledge society that had been created for the past three decades by both countries.

The paper categorised knowledge into two main streams, knowledge wealth and knowledge capital. It is considered that knowledge wealth has been described as the sum total of knowledge assets, or symbolic structures in society while knowledge capital is that part of knowledge wealth used in producing new knowledge, which in turn leads to the further growth of knowledge wealth (Lursadi et al., 2017). The following sections details a systematic approach on how a knowledge society can create a sustainable knowledge based economy.

\section{METHODOLOGY}

The study involved qualitative and quantitative analysis of existing policies in Zimbabwe and India then benchmarked with other countries.There was extensive literature review with regards to intellectual property (IP) generation, universityindustry collaborations, government policies that support IP generation and commercialisation of intellectual property. Other areas under consideration were policies and procedures for the Indian Patent Office, Zimbabwean Intellectual Property Office (ZIPO) and the World Intellectual Property organisation. An in depth analysis of the following areas was carried out in order to develop the recommended approach for the establishment of a knowledge based economy:

- Number of filed patents against granted patents,

- Effect of patenting on GDP growth,

- Commercialisation strategies for developing nations,

- University-industry collaboration challenges

The methodological approach was:

- To validate, and refine as appropriate, a proposed model of transition from a resource based economy to a knowledge based economy;

- To apply this approach in order to demystify how different factors influence the development of knowledge exchange policies and practices in both developing and developed countries, and how certain factors create complexity or barriers leading to problems in practice; and

- To explore how and where improvements might be made to the transition (in both universities and business), governance or leadership, including the role of improved information in increasing understanding and overcoming barriers to collaboration.

\section{RESULTS}

Transition is regarded as a transformative approach hence the need to understand the current position of the economy prior to recommend a transformation to a knowledge based economy.

\subsection{Creation of a Knowledge based society for a Knowledge Based Economy}

It is a well-known fact that the knowledge society is the backbone of a knowledge based economy (Di nauta et al., 2018). India is very ambitious on becoming a knowledge based economy through its high education curriculum and aggressive drive on IP generation, filling and granting (Dwived and Tripathi, 2018). However, the nation has become too comfortable on being a knowledge society along with Zimbabwe hence beginning to experience brain drain from other developed nations. This is due to lack of clear framework on how to unlock value from the intellectual property in order to improve 
national growth (Hadad, 2017).In order to develop the systematic approach, the researchers considered the World Bank's Knowledge Index (KI) which is illustrated in Figure 1. The KI is based on the three pillars namely (Burdenko and Mudrova, 2018):

- Education - the extent at which the population has received basic education. Therefore, an educated community can use and create knowledge.

- Innovation - it is regarded as the ability of the educated society to create new goods and services to meet the societal needs.

- ICT - information communication technology access and utilisation has a large influence on the knowledge index of a country. A reliable information communication and dissemination system is a requirement for a knowledge based economy.

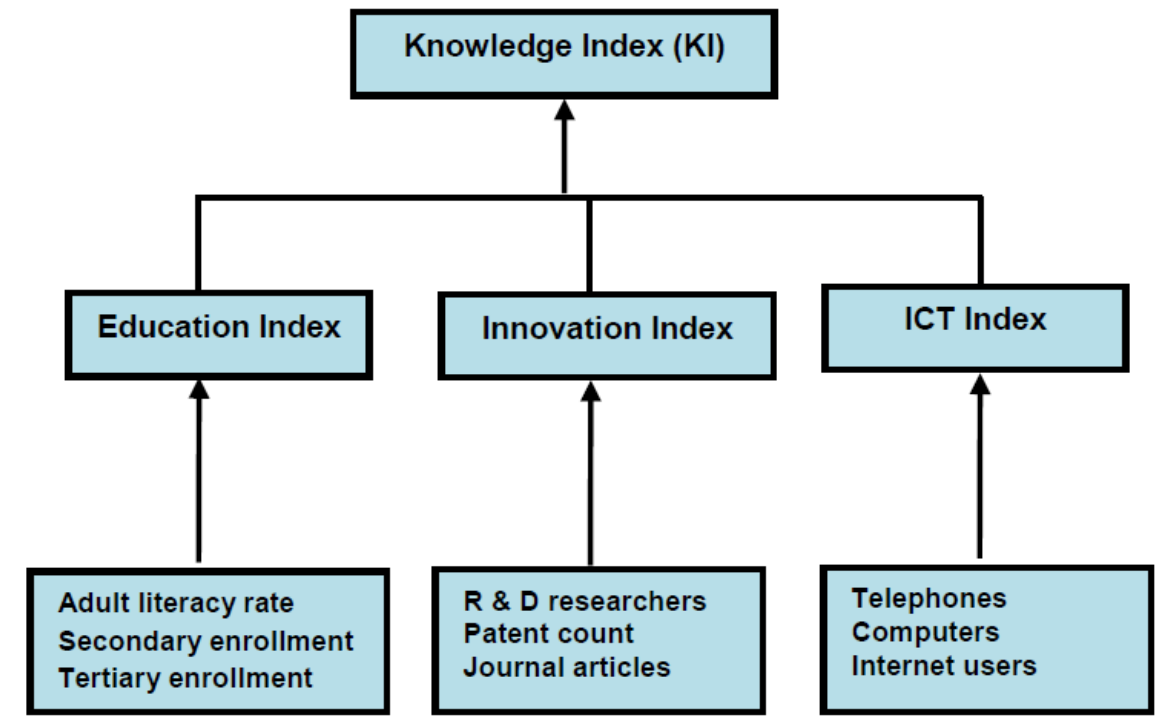

Figure 1: The Knowledge Index Hierarchy

The education index in Zimbabwe and India is skewed positively towards basic education and secondary enrolment (Zapp, 2017). There is a deficiency on tertiary enrolment. Figure 2 illustrates the secondary education enrolment pattern.

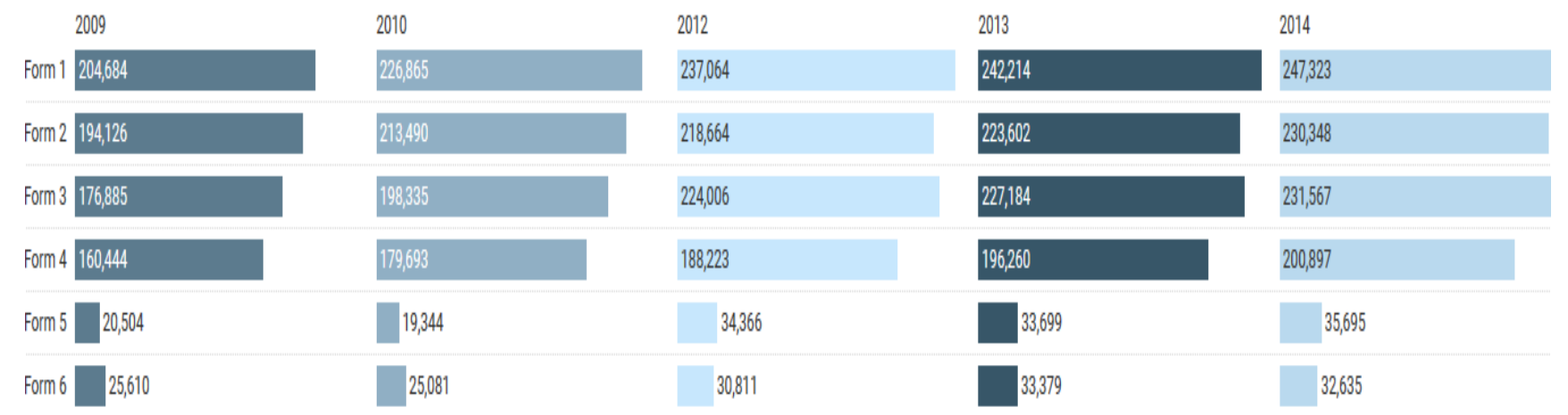

Figure 2: Secondary Education Enrolment

The number of students who completed ordinary secondary education level in Zimbabwe is slightly above 200 
000 students. However, approximately 35000 make it to the advanced secondary level. In Figure 3, the number of students who make it to the universities includes international students and adult learners is over 30000 if we are to exclude agricultural colleges, vocational colleges, technical colleges and teachers' colleges.
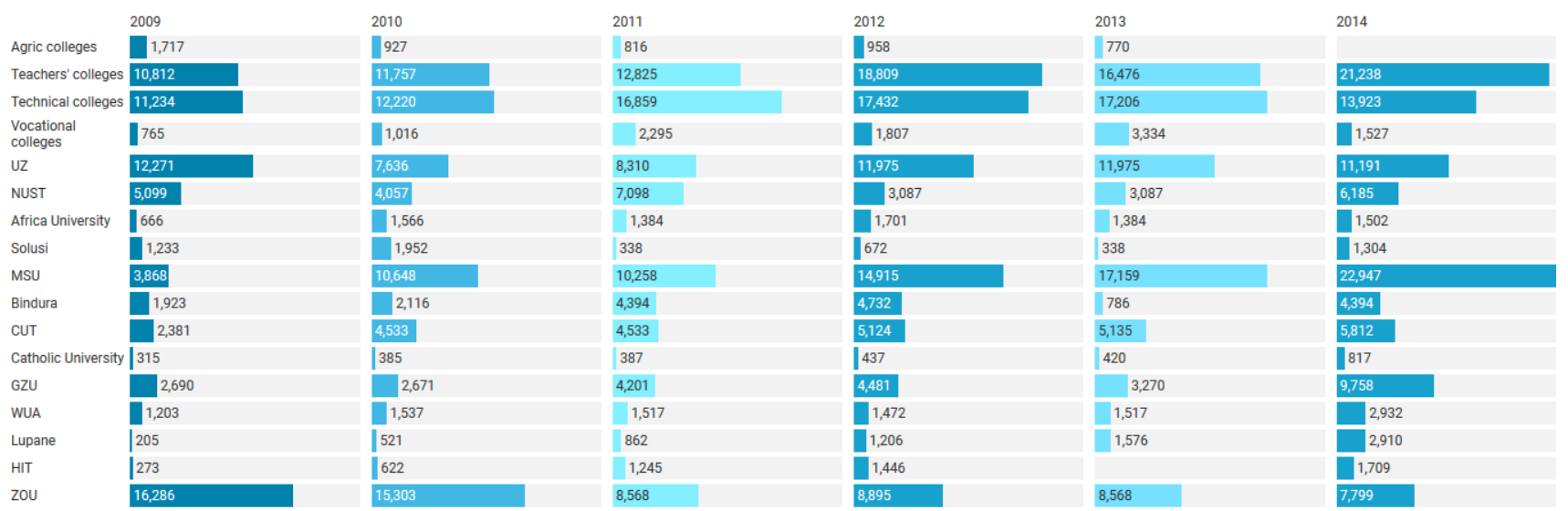

Figure 3: Tertiary Education Enrolment in Zimbabwean Universities

The values in Figure 3 only illustrates the possibility of students who can proceed to MTech and DTech/PhD qualifications. Therefore, there is a lesser number of researchers in Zimbabwe than in India. Zimbabwean researchers do not exceed $15 \%$ of Indian researchers thereby affecting the creation of a Knowledge base economy.

\subsection{Patenting Strategy for Economic Growth}

Intellectual property is regarded as the creation of the mind (Carney et al., 2018). In most cases IP is generated at tertiary education level, hence the need to increase the number of students at tertiary education level. A closer analysis at the total number of researchers against research funding per region indicated that there is a direct relationship as illustrated in Figure 2 (Batabyal and Beladi, 2017). The size of the circles reflects the relative amount of annual R\&D spending by the indicated country. Note the regional grouping of countries by the colour of the balls. 


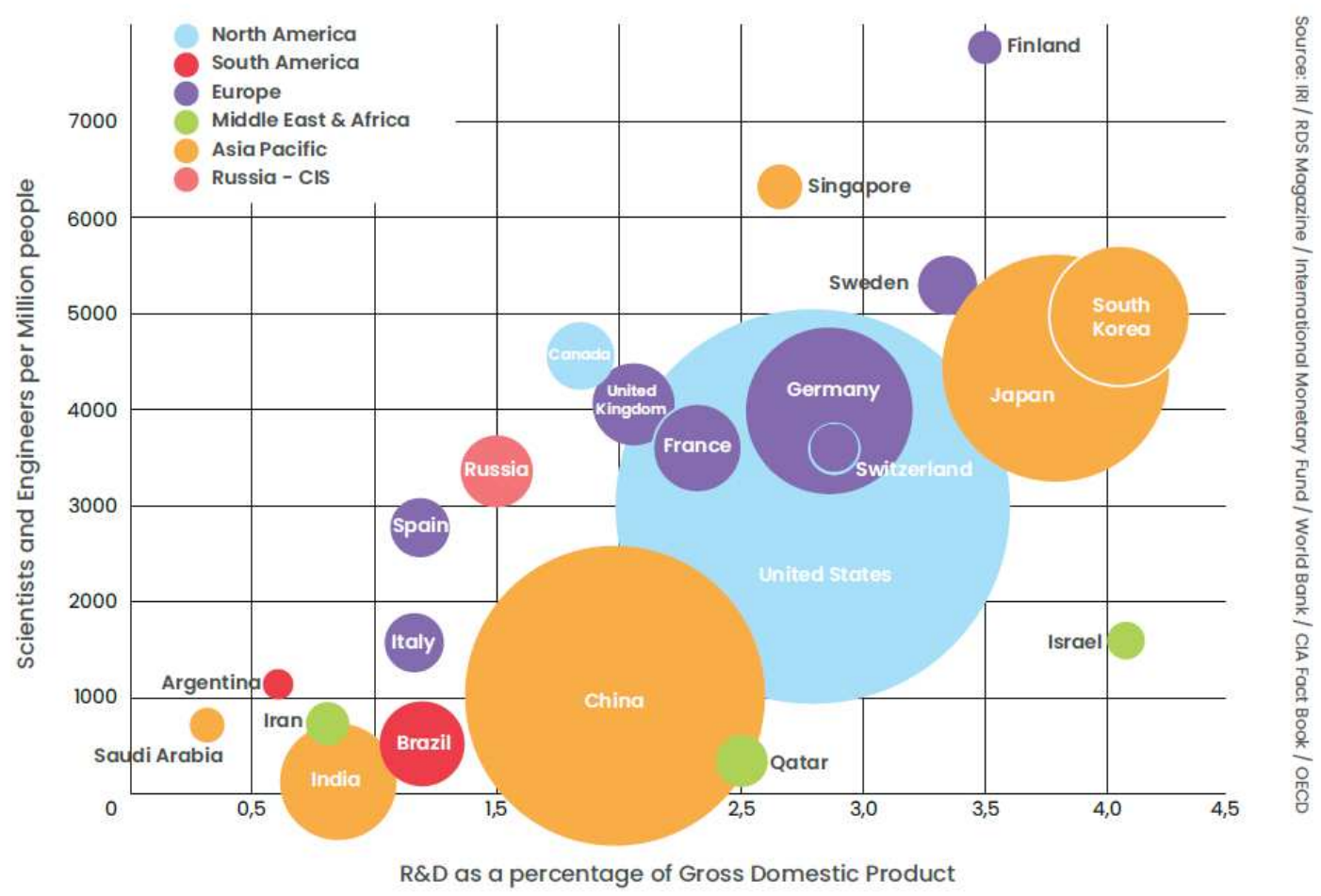

Figure 3: Relationship between Number of Researchers and Gross Domestic Output.

The diagram above illustrates that India has less than 1000 renown researchers and engineers per million people as compared to Japan and South Korea yet India has the largest population than any of the two other Asian countries (Uma and Varatharajan, 2019). It buttresses the issue that India's educated population is skewed towards the tertiary education and social sciences. There is a need to invest in creation of a large population of distinguished researchers. Although the Indian economy is recording a boom, the contribution of research outputs to the Gross Domestic Product (GDP) is less than $2.5 \%$ while that of Israel is above $4 \%$ even though India is spending more ten times more than Israel in research and development (Naikaet al., 2017).

Hi-tech companies are the current leaders in emerging markets. For India to be able to increase its experts there is a great need to tap into emerging markets other than concentrating on traditional markets. However, unique products and innovative business enterprises are established through the acquisition of quality IP rights.Table 1 shows the number of successfully granted IP rights by World Intellectual Property Organisation (WIPO). Due to the stringent submission and claim measures recently implemented in 2018 by WIPO (He, 2019) the number of successful IP claims has significantly decreased across the globe. However, India managed to only have 49 IP rights granted by September 2018 for the year 2018 alone.

Table 1: Patent Granted per Country (Source: WIPO September 2018 report)

\begin{tabular}{|l|l|c|c|c|c|c|}
\hline & Country & $\mathbf{2 0 1 4}$ & $\mathbf{2 0 1 5}$ & $\mathbf{2 0 1 6}$ & $\mathbf{2 0 1 7}$ & $\mathbf{2 0 1 8}$ \\
\hline 1 & China & 679,539 & 825,711 & $1,027,997$ & $1,115,267$ & 835,170 \\
\hline 2 & India & 3,674 & 3,385 & 2,665 & 1,588 & 49 \\
\hline 3 & Japan & 235,314 & 228,741 & 229,034 & 127,452 & 11,310 \\
\hline 4 & United States of America & 163,022 & 162,809 & 158,501 & 96,081 & 9,259 \\
\hline 5 & Zimbabwe & 1 & 3 & 1 & 1 & \\
\hline
\end{tabular}

Comparing with China and Japan in the same Asian region as India, the Indian successful patents have never 
reached $10 \%$ of their counterparts. However, Zimbabwe has barely exceeded $1 \%$ of Indian IP rights achievements. This is a cause of concern considering the number of submissions done by India in 2018 as illustrated in Figure 4.

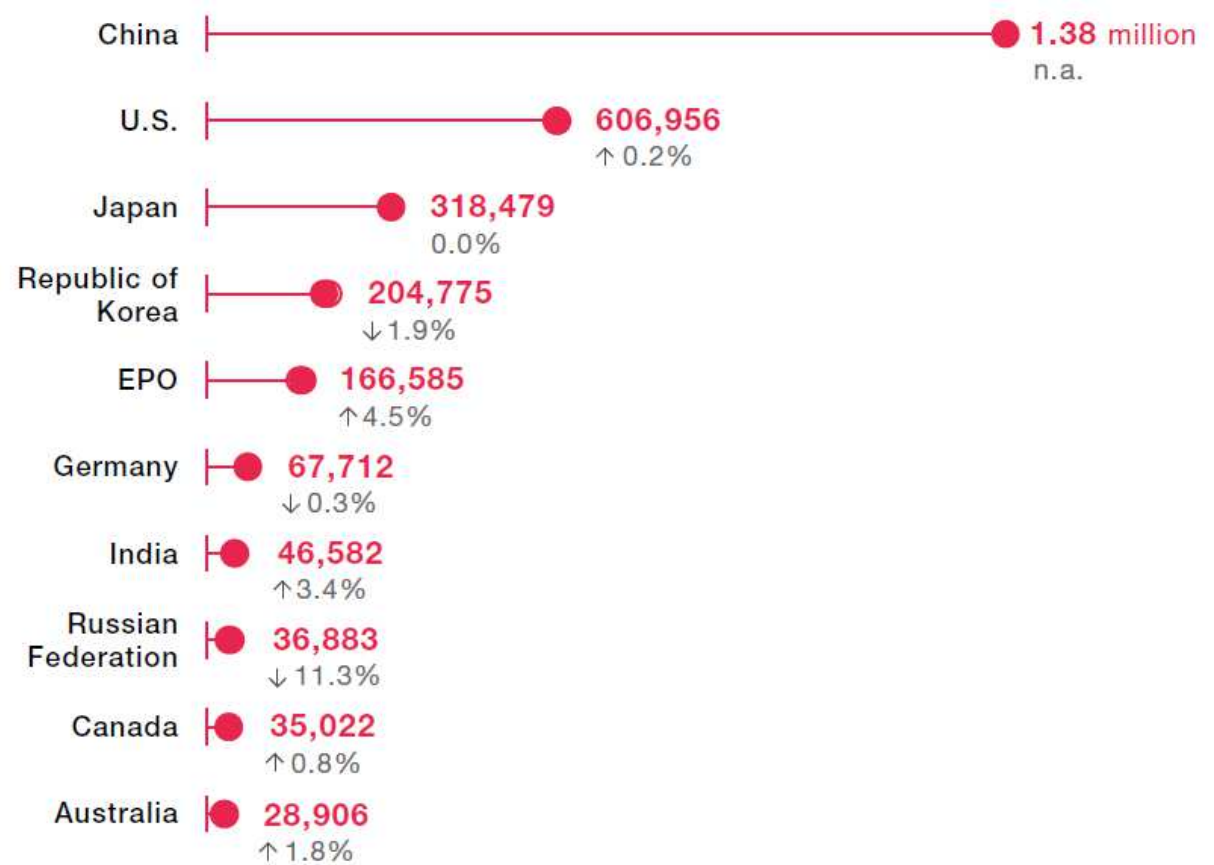

Figure 4: Global Patent Fillings for the year 2018, as at September 2018.

India's patent filing increased by 3.4\% from 2017 to 2018. However, taking into consideration the results on Table 1 , only approximately $0.002 \%$ of the fillings were granted. It somehow shows the need for quality improvement on the type of submissions. Trademarks are a major contributor to a knowledge based economy, Figure 5 illustrates the number of trademarks achieved by India relative to other developed countries in 2018.

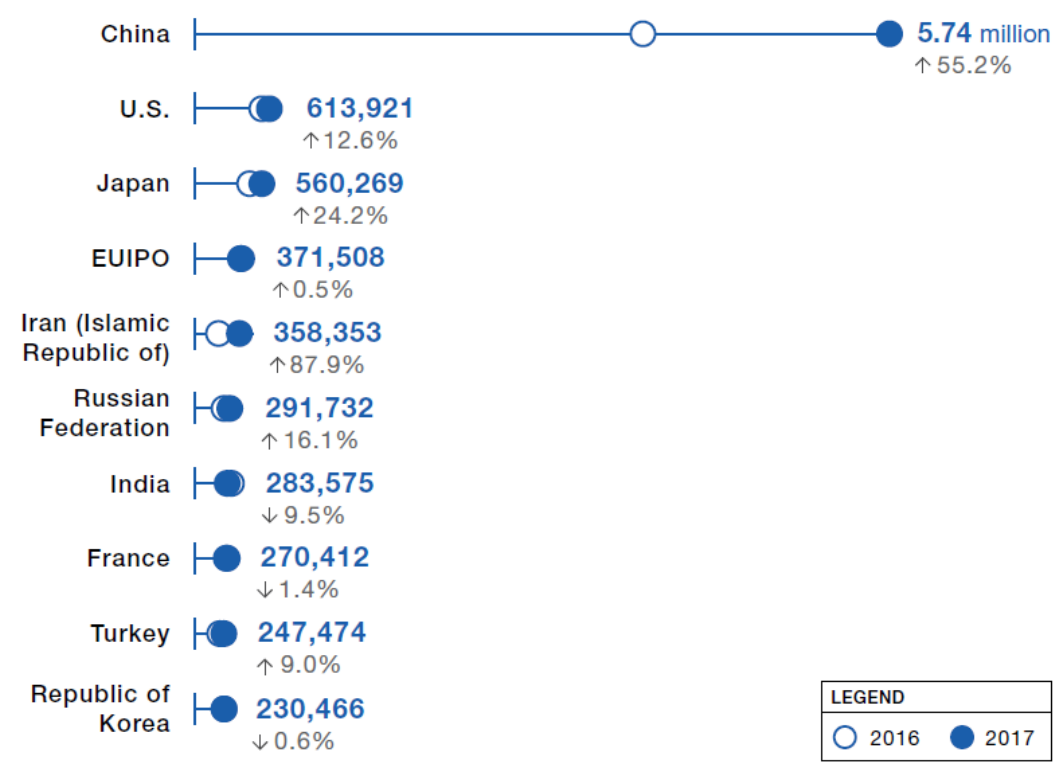

Figure 5: Trademarks Granted as at September 2018.

Surprising as it seems India is doing well on trademarks as compared to other European and African countries. However, its contribution to global number of trademarks is less than $0.05 \%$ to that of China. This hint out on the fact of 
the rapid growth of the Chinese Knowledge based economy.

\subsection{Infrastructure as a Requirement for Transition from Resource Based Economy to Knowledge Based Economy}

The third requirement for a successful transition is infrastructure. In this section an in depth analysis was carried out for India and Zimbabwe with comparison to Japan, America and China. India has managed to establish state of the art infrastructure for research and development. There are a quite a number of specific centres of excellence across India. These centres provide infrastructure for local, regional and international researchers thereby increasing the number of publications (Ninawe and Indulka, 2019). However, it is not the number of publications made that maters but the ability of the institutions to commercialise the research outputs. Table 2 below shows the number of research centres in India and their respective research focus.

Table 2: India Research Centres (source :http://dst.gov.in/sites/default/files/ANNEXURE-I\%20-List-of-Indian-institutions.pdf )

\begin{tabular}{|l|c|}
\hline \multicolumn{1}{|c|}{ Areas of Research } & Total \\
\hline Agricultural Sciences & 66 \\
\hline Biological and Medical Sciences & 60 \\
\hline Chemical Sciences & 09 \\
\hline Physical Sciences and Mathematics & 16 \\
\hline Earth Sciences & 16 \\
\hline Engineering Sciences & 23 \\
\hline Materials, Minerals and Metallurgy & 09 \\
\hline Multi-disciplinary and Other Areas & 17 \\
\hline \multicolumn{2}{|c|}{ Total } \\
\hline
\end{tabular}

A total of 216 research centres excluding universities is a very large number for the creation of a knowledge based society which is key for the transition to a knowledge based economy. There are further over a hundred institutes of national importance. As of February 2017, there are 789 universities, 37,204 colleges and 11,443 stand-alone institutions in India. These figures are a massive number for economic development. The establishment of these centres shows the commitment of the Indian government and the private sector to create a knowledge based society.

Incubation and innovation hubs are some of the requirements for the transition process, with 140 incubators and accelerators, India has inched past Israel, whose count stands at 130 (Scillitoe, 2019). However, the gap with the top two is still yawning - China and the US have over 2,400 and 1,500 incubators and accelerators, respectively. However, the Indian government through the Department of Science and Technology has embarked on a drive to assist each and every university to have an innovation hub (Singh, 2019).

On the other hand, Zimbabwe has established over 12 universities and 8 research centres but most of the research centres in Zimbabwe are aligned to agriculture research work. Majority of Zimbabwean universities are state-owned hence the government is the major research funder. Since 2018, the government of Zimbabwe has started to build innovation hubs on six of the state universities who are technologically aligned.

\section{DISCUSSIONS}


The findings from literature presented in the previous section highlighted that knowledge based society, patenting and infrastructure are the key factors from transforming India from a resource based economy to a knowledge based economy. However, on Figure 1, the Knowledge Index by World Bank there is a need to include a $4^{\text {th }}$ pillar that shows contribution by the government as illustrated in Figure 6 bellow.

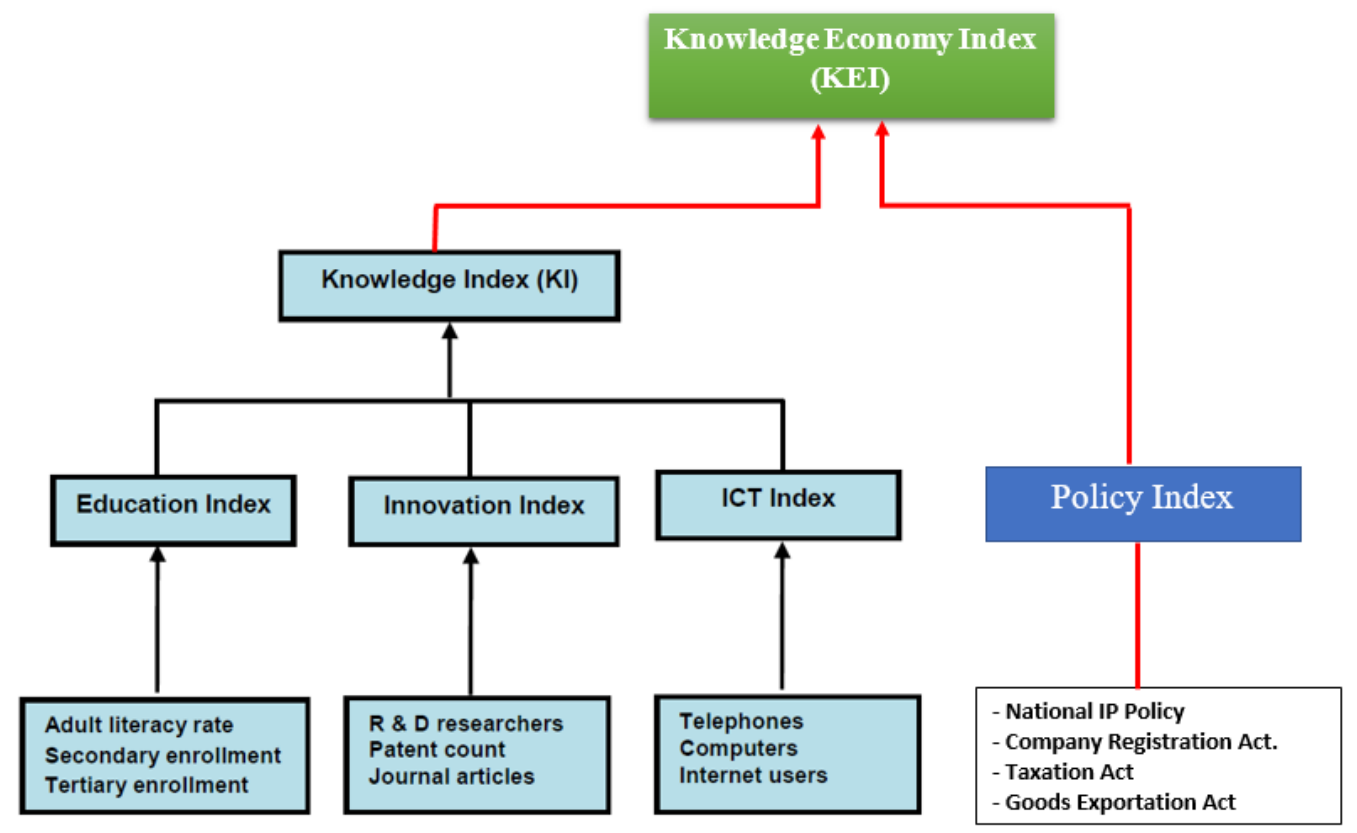

Figure 6: The Systematic Approach to Knowledge Economy

In Figure 6, the researchers have advocated for the additional Policy Index in order to create an enabling environment for the creation of a knowledge economy. The current policies are aligned towards the resourced based economies making it difficult to unlock value from patented research outputs. There is great potential growth for a knowledge based economy as it reduces imports, creates jobs and increase foreign currency generation through a surge in exports (Frias et al., 2020).

Rajastan government is targeting 39000 startup companies which are a direct creation of patented technology. To date they have over 1000 start-ups and created jobs between 5000-6000 for the youths in particular. T-Hub in Hyderabad has established over 1440 startup companies since its establishment in 2015 and is in the centre of India's IT ecosystem. Bengaluru is the current main driver for the Indian Knowledge Base economy, as many as 9,346 tech startups have been launched in the city since 2010, with as many as 5,541 of them being launched in the last three years itself, the highest in the country. With 14 unicorns with a cumulative valuation of $\$ 61$ billion, Bengaluru has been the biggest driver of the India startup growth story, according to the report. It predicts that the city is poised to grow even more rapidly with $43 \%$ of soonicorns (potential unicorns) having or going to establish their base in Bengaluru.

Such initiative by federal governments should be complimented with favourable policies to support the ever increasing enterprises who are aligned to the establishment of a Knowledge Based economy. Bengaluru-based startups have raised around $\$ 31$ billion in the last decade, which is approximately $45 \%$ of the total investment into the Indian startup ecosystem. The city is the preferred destination for late stage investors with around 55\% of Series D+ investments in the country flowing into local startups. However, if the Policy Index does not reflect a good investment environment the Foreign Direct Investment (FDI) in that region will be depleted in the next few years. Figure 7 illustrates the revolutions 
that affected world economies and knowledge revolution is the current phase.

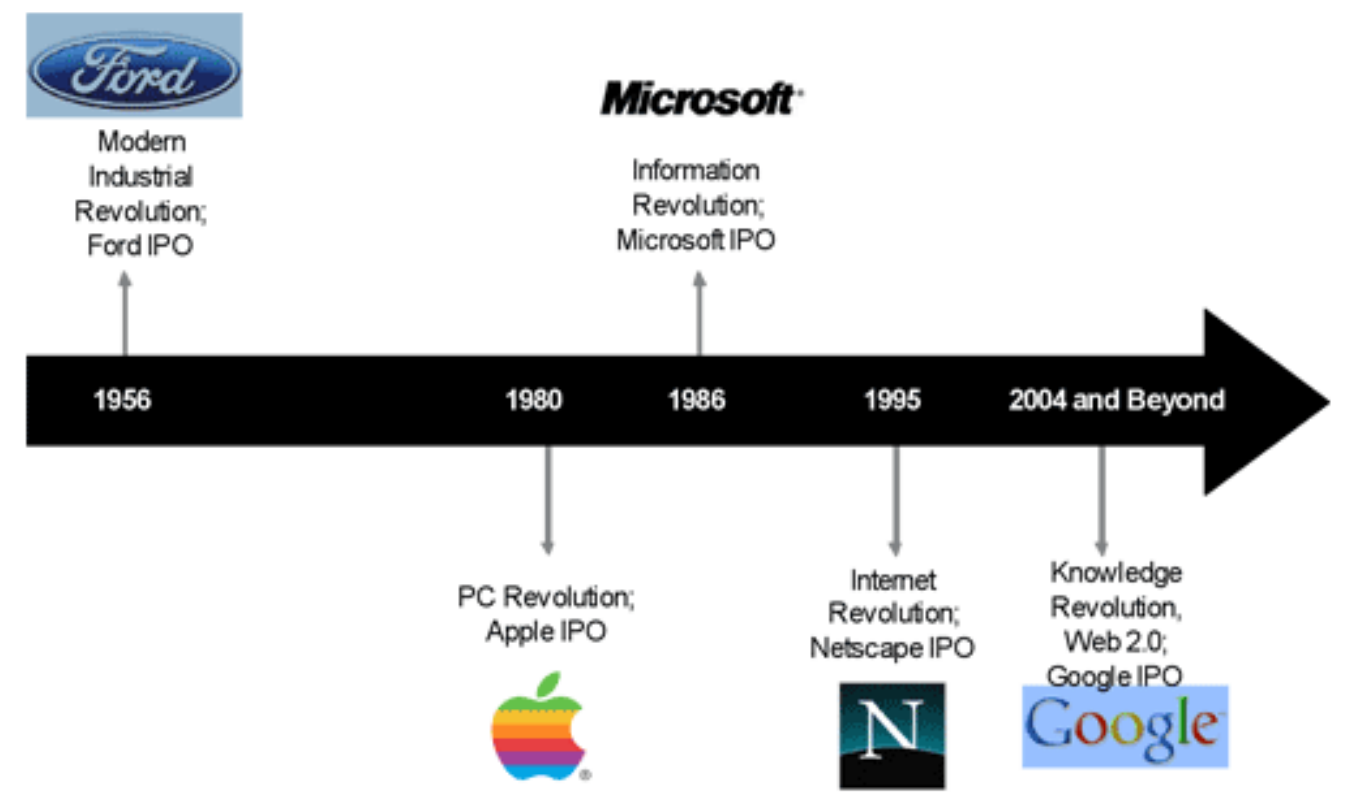

Figure 7: Evolutions for Economy Drivers

In the $19^{\text {th }}$ century the automobile industry managed to sustain the economy of several nations. However, in the $21^{\text {st }}$ century tides have turned towards knowledge revolution which signifies Knowledge Based Economy (KEB) (Sorensen et al, 2016). Due to their ability to unlock value from research the largest taxi company has no taxies (Uber) and the largest Hotel company has no hotels (Airbnb). This symbolises the knowledge evolution. Figure 7 shows the world R\&D outsourcing expenditure.

\section{Annual World R\&D Expenditures 1926 Billion \$*}
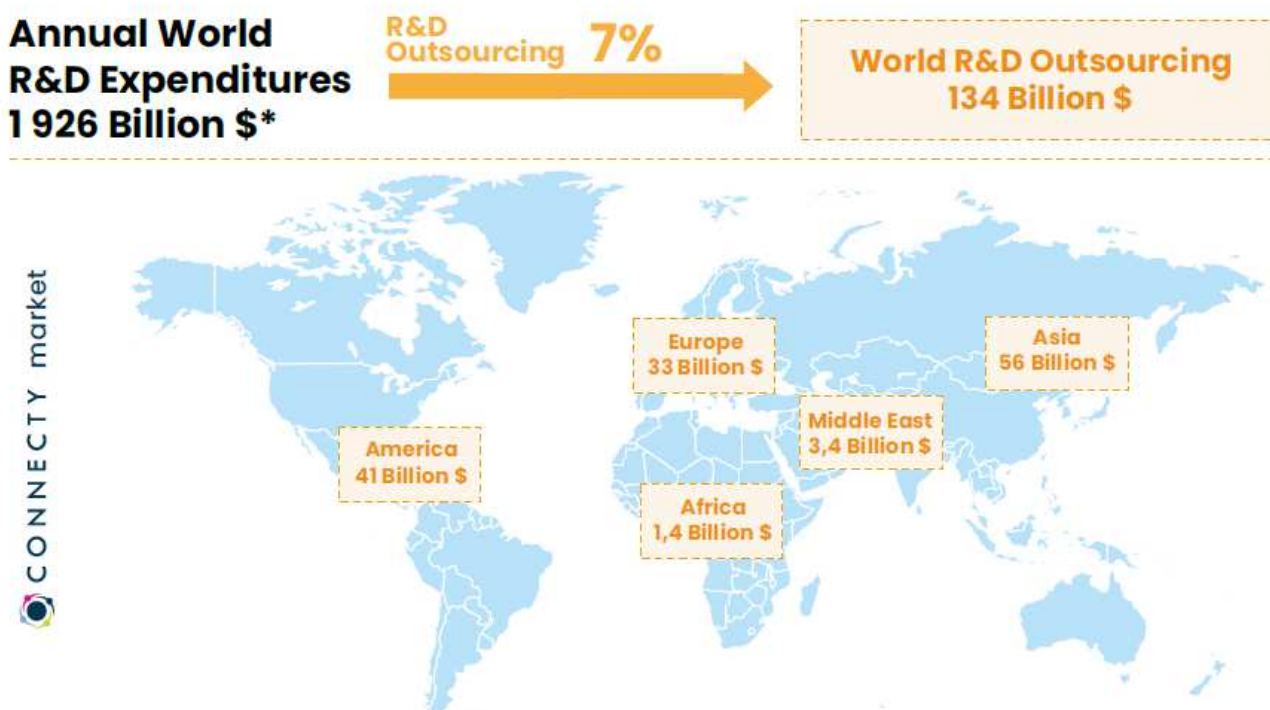

Figure 8: The R\&D Expenditure Outsourcing per Continent (Source: UNESCO 2015 report)

According to Karatisli (2017), the world outsources over 134 Billion US\$ of which the Asian community does outsource US\$ 56 Billion that's approximately $42 \%$ of the world expenditure on outsourced R\&D. This indicates that Asia alone is a potential market for India to offer its services to the neighbouring countries. The major set-back is that India's 
technologies are not being patented and majority of the industry players are SMEs (Rajavenkatesanet al., 2020). The government needs to create policies that promotes exportation of products and services by the SMEs in order to capture the available markets.

\section{CONCLUSIONS}

A systematic approach to the establishment of a Knowledge Based Economy (KBE) from the existing Resource Based Economy (RBE) in India and Zimbabwe was presented. Knowledge Based Society (KBS) is the key for the transformation from RBE to KBE, hence India already has a functional KBS that can easily be utilised for a rapid transition into a KBE. India's KBS has generated a substantial number of patents which are yet to be commercialised. It is the commercialisation strategy that sustain the KBE. To achieve that the researchers created a framework that includes Political Index (measure of government contribution). However, government policies procedures currently inhibit the creation of the KBE due to misalignment between trade policies and research policies.

\section{ACKNOWLEDGEMENT}

I want to thank Amity University Haryana and Harare Institute of Technology for their funding support which has gone a long way in making this study a success.

\section{REFERENCES}

1. Boden, M. and Miles, I., 2019. Services and the Knowledge-based Economy. Routledge.

2. Nurunnabi, M., 2017. Transformation from an oil-based economy to a knowledge-based economy in Saudi Arabia: the direction of Saudi vision 2030. Journal of the Knowledge Economy, 8(2), pp.536-564.

3. Fessehaie, J. and Rustomjee, Z., 2018. Resource-based industrialisation in Southern Africa: Domestic policies, corporate strategies and regional dynamics. Development Southern Africa, 35(3), pp.404-418.

4. Becker, U., Fernandes, T., Arora, R., Banerjee, A. and Saluja, M.S., 2019. The Indian Resource Panel: A Mechanism to Promote Resource Efficiency Policy Throughout the Indian Economy. In Waste Management and Resource Efficiency (pp. 275-285). Springer, Singapore.

5. North, K. and Kumta, G., 2018. Knowledge management: Value creation through organizational learning. Springer.

6. Friederici, N., 2019. Innovation Hubs in Africa: What Do They Really Do for Digital Entrepreneurs? In Digital Entrepreneurship in Sub-Saharan Africa (pp. 9-28). Palgrave Macmillan, Cham.

7. Lusardi, A., Michaud, P.C. and Mitchell, O.S., 2017. Optimal financial knowledge and wealth inequality. Journal of Political Economy, 125(2), pp.431-477.

8. Di Nauta, P., Merola, B., Caputo, F. and Evangelista, F., 2018. Reflections on the role of university to face the challenges of knowledge society for the local economic development. Journal of the Knowledge Economy, 9(1), pp.180-198.

9. Dwivedi, G. and Tripathi, M., 2018. Association of Indian Universities. UNIVERSITY NEWS, 56, p.29.

10. Burdenko, E.V. and Mudrova, S.V., 2018. Indicators System as a Measure of Development Level of Knowledge Economy: Application of World Bank Methodology. In Global Practices in Knowledge Management for Societal and Organizational Development (pp. 74-105). IGI Global.

11. Zapp, M., 2017. The World Bank and education: Governing (through) knowledge. International Journal of Educational Development, 53, pp.1-11. 
12. Carney, M., Zhao, J. and Zhu, L., 2018. Lean innovation: Family firm succession and patenting strategy in a dynamic institutional landscape. Journal of Family Business Strategy.

13. Batabyal, A.A. and Beladi, H., 2017. Patent protection in a model of economic growth in multiple regions. Networks and Spatial Economics, 17(1), pp.255-268.

14. Uma, V. and Varatharajan, N., 2019. Publishing Pattern of Faculty Members in University of Hyderabad: An Analytical Study. Pearl: A Journal of Library and Information Science, 13(2), pp.151-166.

15. Naika, M., Kanamadi, S. and Jotwani, D., 2017. Mapping of Innovations at Indian Institute of Technology Bombay: a Scientometric Approach. SRELS Journal of Information Management, 54(2), pp.85-90.

16. He, J., 2019. Indian Patent Law and Its Impact on the Pharmaceutical Industry: What Can China Learn from India?. In Innovation, Economic Development, and Intellectual Property in India and China (pp. 251-269). Springer, Singapore.

17. Mitra, A., 2018. Reflecting on India's Development: Employment, Skill and Health. Springer.

18. Scillitoe, J.L., 2019, July. Incubation of Technology Startups in India. In Academy of Management Proceedings (Vol. 2019, No. 1, p. 10162). Briarcliff Manor, NY 10510: Academy of Management.

19. Singh, L., 2019. Startup India initiative-A comparative study of selected states. Pranjana: The Journal of Management Awareness, 22(1), pp.1-10.

20. Frias, J., Shimbov, B., Davies, E. and Ek, C., 2020. Serbia's New Growth Agenda: Increasing Exports.

21. Rajavenkatesan, P.R.L., Prema, E. and Sundar, V.S., 2020. PATENTING OF BUSINESS METHODS: ISSUES AND CHALLENGES. International Journal of Management, 11(04).

22. Sorensen, M.P., Bloch, C. and Young, M., 2016. Excellence in the knowledge-based economy: from scientific to research excellence. European Journal of Higher Education, 6(3), pp.217-236.

23. Karataşlı, S.S., 2017. The Capitalist World-Economy in the Longue Durée: Changing Modes of the Global Distribution of Wealth, 1500-2008. Sociology of Development, 3(2), pp.163-196.

24. Handayati, P. (2015). The Grand Design Of Cooperative Roles In East Java To Support The Masterplan Of The Acceleration And The Expansion Of Indonesian Economy Development (Mp3ei).

25. Pallavi, E., \&Bhanu, M. (2016). Green Hrm: A Way For Corporate Sustainability.

26. Aderonmu, P. A., Adewale, B. A., Alagbe, O. A., \& Dare-Abel, O. A. (2014). Sustainability Parameters in Knowledge Construction: Energy Efficiency Issues of Architectural Design Studio Space. International Journal of Civil, Structural, Environmental and Infrastructure Engineering Research and Development (IJCSEIERD, 4(6), 11-18. 

